\title{
A CONSTRUÇÃO TÁTICA NO VOLEIBOL: ENSINO PELA COMPREENSÃO
}

Leopoldo Katsuki Hirama, Universidade Federal do Recôncavo da Bahia - UFRB, Amargosa, Bahia - Brasil

Cássia dos Santos Joaquim, Universidade Estadual de Campinas - UNICAMP, Campinas, São Paulo - Brasil

José Arlen Beltrão de Matos, Universidade Federal do Recôncavo da Bahia - UFRB, Amargosa, Bahia - Brasil

Paulo Cesar Montagner, Universidade Estadual de Campinas - UNICAMP, Campinas, São Paulo - Brasil

\section{RESUMO}

O voleibol é muito conhecido e praticado no Brasil. No entanto sua iniciação enfrenta problemas diante de sua própria dinâmica, realizada através de rebatidas na bola, ao contrário da maioria dos esportes coletivos. Tradicionalmente se busca resolver tal dificuldade através do ensino das técnicas básicas, estimulando o domínio da bola, para posteriormente propor a aprendizagem de suas táticas. Este estudo apresenta uma proposta aplicada em duas instituições com jovens iniciantes no voleibol estimulando seu ensino com ênfase em situações táticas. Os resultados demonstraram que a compreensão da dinâmica do jogo e a resolução dos problemas oriundos destas situações provocaram o entendimento e versatilidade das diferentes funções na modalidade e a importância do domínio técnico.

Palavras-Chave: Voleibol; Iniciação esportiva; Sistemas de jogo.

\section{CONSTRUCTION TACTICS IN VOLLEYBALL: EDUCATION FOR UNDERSTANDING}

\begin{abstract}
The volleyball is very known and practiced in Brazil. However, initiation of the sport faces problems because its own dynamics is performed batting the ball, unlike most of team sports. To resolve this problem, traditionally is taught the basic techniques, stimulating the domain of the ball, later to propose learning their tactics. This study presents a proposal applied in two institutions with young beginners in volleyball with an emphasis on tactical situations. The results showed that the understanding of the game dynamics and the resolution of problems arising from these situations led to the understanding and versatility of the different functions in the sport and the importance of the technical field.
\end{abstract}

Key-Words: Volleyball; Sports initiation; Tactic.

Conexões: revista da Faculdade de Educação Física da UNICAMP, Campinas, v. 13, n. 4, p. 165-177, out./dez. 2015. ISSN: 1983-9030. 


\section{LA CONSTRUCCIÓN DE LA TÁCTICA EN VOLEIBOL: ENSEÑANZA PARA LA COMPRENSIÓN}

\section{RESUMEN}

El voleibol es muy conocido y practicado en Brasil. Sin embargo, la iniciación de este deporte se enfrenta a problemas debido a sus propias dinámicas realizadas por rebater la bola, a diferencia de la mayoría de los deportes de equipo. Tradicionalmente busca resolver esta dificultad mediante la enseñanza de las técnicas básicas, estimulando el dominio del balón y sólo más tarde proponer aprender sus tácticas. Este estudio presenta una propuesta aplicada en dos instituciones con jóvenes principiantes en el voleibol que estimularon su educación con énfasis en situaciones tácticas. Los resultados mostraron que la comprensión de la dinámica del juego y la resolución de los problemas derivados de estas situaciones llevaron a la comprensión y la versatilidad de las diferentes funciones en el deporte y la importancia del ámbito técnico.

Palabras-Clave: Voleibol; Iniciación deportiva; Táctica. 


\section{INTRODUÇÃO}

O voleibol é um dos esportes coletivos mais praticados e conhecidos no Brasil. Segundo o Atlas do Esporte no Brasil, ${ }^{1}$ existem 15 milhões de praticantes, sendo considerado a $2^{\mathrm{a}}$ modalidade mais praticada no país.

O grande número de adeptos e admiradores pode ser atribuído ao sucesso das equipes representativas nacionais no cenário mundial, figurando entre as 4 melhores há pelo menos duas décadas, tanto no gênero masculino como no feminino. ${ }^{2}$

No entanto, quando nos reportamos ao ensino desta modalidade, algumas características do jogo dificultam seu aprendizado, a começar por sua própria dinâmica determinada pela regra que proíbe a retenção da bola com as mãos enquanto esta estiver em jogo. ${ }^{3}$ Desta forma, atua-se integralmente rebatendo-se a bola, forma bastante diferente das demais modalidades coletivas mais conhecidas no país. E para acentuar a dificuldade do jogo, a bola não pode atingir o solo de seu próprio campo.

Diante de tais desafios, é comum iniciar o ensino da modalidade a partir do aprendizado de suas técnicas, ${ }^{4}$ na busca por preparar seus praticantes a controlarem a bola dentro do que a regra permite: através de rebatidas, limitadas por apenas 3 toques entre seus companheiros sem deixá-la atingir o solo de seu lado direcionado a bola para o campo adversário. Dificultando ainda mais, a rebatida necessita obedecer a critérios técnicos que exigem precisão, coordenação adequada, a exemplo do toque por cima da cabeça, ${ }^{3}$ correndo o risco de ter sua ação penalizada, representando ponto ao adversário.

Para enfrentar tais dificuldades apresentadas na modalidade, as propostas tradicionais são baseadas em aulas com muitas repetições de fundamentos como a manchete, toque, saque, entre outros. Grecco ${ }^{5: 16}$ destaca um dos problemas deste método de ensino:

Dedica-se muito tempo ao ensino da técnica; as aulas, normalmente, são monótonas, geralmente analíticas; praticamente nada do que compõe o jogo é transferido logo à situação real do mesmo.

Conexões: revista da Faculdade de Educação Física da UNICAMP, Campinas, v. 13, n. 4, p. 165-177, out./dez. 2015. ISSN: 1983-9030. 
Desta forma, os aspectos táticos relacionados à compreensão da dinâmica do jogo, desde as mais fundamentais como, defesa de seu espaço e possibilidades de fazer com que a bola atinja o solo do campo adversário, são deixados em segundo plano. Cria-se um hiato entre as partes do jogo e sua própria dinâmica, enfatizando nos iniciantes as respostas de como controlar a bola utilizando as técnicas, abdicando de colocá-las diante de problemas como o porquê, quando e de que forma utilizar tais fundamentos.

Diante do exposto, este relato tem por objetivo apresentar uma proposta de ensino do voleibol que procurou estimular o entendimento da dinâmica do voleibol, buscando reflexões táticas gradativamente mais complexas, paralelamente ao desenvolvimento das técnicas próprias da modalidade de forma consciente, estimulando nos alunos a compreensão das funções de cada uma delas.

Estas experiências foram vivenciadas em 2 espaços educacionais e tiveram duração de 3 anos cada. O primeiro espaço refere-se a uma Organização Não-Governamental (ONG) que oferecia aulas de voleibol na cidade de Campinas, para crianças e jovens de 7 a 15 anos. Este relato refere-se especificamente ao grupo mais velho feminino (média de 15 anos). Neste período passaram pela equipe 15 adolescentes, mantendo-se um núcleo comum de 9 alunas/atletas durante todo o período. No início das atividades, com exceção de duas alunas, as demais não tinham qualquer experiência anterior com a modalidade. $\mathrm{O}$ grupo participou de vários campeonatos, torneios e festivais, culminando na participação nos Jogos Regionais do Interior do estado de São Paulo já na categoria sub 21ficando em sua última participação na quinta colocação na categoria sub 21.

O segundo espaço deste relato refere-se à equipe masculina composta por meninos de 15 anos participantes de um projeto socioeducativo na favela de Heliópolis, São Paulo, organizado por outra ONG, patrocinada por uma grande multinacional. Foram 14 componentes do grupo que se mantiveram unidos também durante 3 anos, participando de campeonatos regionais. Nenhum dos alunos tinha qualquer experiência anterior com a modalidade.

Conexões: revista da Faculdade de Educação Física da UNICAMP, Campinas, v. 13, n. 4, p. 165-177, out./dez. 2015. ISSN: 1983-9030. 


\section{RESULTADOS E DISCUSSÃO: CONSTRUINDO A FORMA DE JOGAR}

Decidiu-se relatar o processo vivenciado nas duas equipes, pois a proposta foi a mesma e muitos resultados se mostraram semelhantes. Em linhas gerais a trajetória vivenciada baseou-se no ensino do voleibol com ênfase no jogo, ${ }^{1}$ invertendo-se a lógica descrita anteriormente, partindo, desta forma, do todo (o jogo) para as partes (as técnicas). A dinâmica básica é apresentada e a partir das situações ocorridas buscou-se o aprendizado das técnicas de forma a tornar consciente os motivos de sua utilização. Reforçam esta situação Reverdito e Scaglia ${ }^{4: 64}$ quando afirmam que “[...] a técnica deverá ser desenvolvida em virtude de uma necessidade tática no jogo e ser reconhecida neste pelo aluno.”

Serão descritos a seguir, na forma de tópicos para melhor compreensão, as fases pelas quais os grupos passaram e os relativos problemas situacionais a serem enfrentados como também as respostas apresentadas:

\section{SISTEMA 6X0 COM LEVANTAMENTO NA POSIÇÃO 3}

A dinâmica iniciou-se a partir da participação de todos os alunos em todas as posições. Mesmo em jogos reduzidos, 2X2, 3X3 ou 4X4, efetuava-se sempre o rodízio (rotação tradicional dos jogadores nas posições) para que vivenciassem a atuação em qualquer posição existente. Nos jogos em sexteto, este sistema é conhecido como 6X0, ou seja, 6 atacantes, para nenhum levantador específico. Os jogadores assumiram a função de levantador quando atuavam em determinada posição. Inicialmente, o jogador que estivesse na posição 3 (no centro e na rede) era o levantador.

Reconhecido como o sistema mais simples, os alunos se deparavam com problemas situacionais gerais como direcionamento da bola na recepção do saque, levantamento para as pontas da rede e ajustes do atacante para conseguir cortar a bola levantada. Cada um dos problemas oferecia oportunidade de discussão sobre maneiras de serem resolvidos.

\footnotetext{
${ }^{1}$ A proposta é fundamentada por autores como Kroger e Roth; ${ }^{6}$ Oslin; ${ }^{7}$ Reverdito e Scaglia; ${ }^{4}$ e Souza ${ }^{8}$. Conexões: revista da Faculdade de Educação Física da UNICAMP, Campinas, v. 13, n. 4, p. 165-177, out./dez. 2015. ISSN: 1983-9030.
} 
Algumas regras adaptadas foram utilizadas nos jogos com o objetivo de diminuir o ritmo do jogo ${ }^{2}$ e proporcionar maior tempo e liberdade para a resolução dos problemas. Segundo Graça e Oliveira: ${ }^{10: 67}$

O ponto de partida desta abordagem assenta na formulação de uma forma modificada do jogo, necessariamente mais simples, adequada aos níveis actuais de interpretação dos alunos e ao mesmo tempo facilitadora da aquisição dos conceitos e competências associados à operacionalização da ideia de bom jogo para esse nível.

Como exemplo, apenas o jogador que estivesse na posição 3 poderia segurar a bola antes de executar o levantamento. Esta paralisação temporária estimulava nos alunos:

- Para quem recepcionou a bola, verificar como foi seu desempenho, se realmente conseguiu direcionar bem a bola e na altura correta;

- Para o levantador, verificar quais as possibilidades de atacantes e a distância que deverá direcionar a bola para o levantamento correto;

- Para os possíveis atacantes, refletir sobre como se preparar para executar a cortada, inclusive avaliando como seu companheiro levantador costuma executar esta ação.

Esta regra foi utilizada até o final do sistema descrito a seguir, de forma pontual e sempre como possibilidade e não como obrigação em segurar a bola.

\section{SISTEMA 6X0 COM LEVANTAMENTO NA POSIÇÃO 4 E 2}

Após a vivência do sistema 6 X0 com levantamento da posição 3, alterou-se a posição de quem seria o levantador para a posição 4 e posteriormente para a posição 2, o que significou realizar o levantamento a partir das extremidades da rede. Os problemas situacionais variaram:

\footnotetext{
${ }^{2}$ Ver também em Souza ${ }^{8}$ e Griffin ${ }^{9}$

Conexões: revista da Faculdade de Educação Física da UNICAMP, Campinas, v. 13, n. 4, p. 165-177, out./dez. 2015. ISSN: 1983-9030.
} 
- Quais os atacantes e de onde eles poderiam atacar levantando-se das extremidades? Surgia a figura do atacante de meio (no centro da rede);

- Como levantar para o atacante de meio? Bolas altas e curtas ou mais baixas? As variações nos levantamentos começavam a surgir; - Como levantar para a outra extremidade da rede? Aprender uma técnica adequada para que o levantamento atravessasse a quadra passou a ser necessário (aqui verifica-se a importância de, inicialmente, ser permitido segurar a bola. Com maior tempo para verificar as possibilidades e seus resultados, uma solução corriqueira que foi apresentada foi a de levantar a bola de forma que ela não fosse tão alta, priorizando assim a distância.

Consequentemente o atacante precisou se adaptar e esta nova situação de cortada com bolas mais rápidas, conhecidas por bolas chutadas);

- Como receber e para onde direcionar a bola oriunda do saque? O centro da rede, que antes significava uma referência de direção variou para as extremidades;

- Como se adequar para atacar os levantamentos mais curtos no centro da rede ou longos que atravessam toda a quadra? Os atacantes aprendendo a cortar nas diversas posições e com tipos de levantamentos diferentes.

Oferecer situações problemas aos alunos pode estimular uma série de ajustes importantes na formação dos alunos, seja na questão técnica e tática do jogo, como ainda nas questões de relacionamento do grupo:

O objetivo é o de desenvolver a inteligência para o jogo, a compreensão da modalidade, como também aspectos de relacionamento como liderança, autonomia, trabalho em grupo, propor ideias e defendê-las, ouvir as dos colegas e acatá-las ou não, agir conforme o acordado coletivo. ${ }^{11: 62}$

Conexões: revista da Faculdade de Educação Física da UNICAMP, Campinas, v. 13, n. 4, p. 165-177, out./dez. 2015. ISSN: 1983-9030. 


\section{SISTEMA 6X0 COM ESCOLHA DO LEVANTADOR}

Neste sistema a equipe, após vivenciar o levantamento de todas as posições da rede, optaria, por livre escolha, quem, dos 3 jogadores da rede, seria o levantador, que o faria da posição em que estaria (posição 2, 3 ou 4), sem trocas ainda. As reflexões foram:

- Dos 3 jogadores que estão na rede, qual o melhor levantador e melhores atacantes? Início da discussão sobre as habilidades e também os desejos de cada jogador;

- De qual posição é melhor para nossa equipe levantar? Reflexão sobre qual situação é mais confortável para a equipe;

- Qual o melhor e pior bloqueio adversário? Apesar deste raciocínio parecer ainda bastante complexo para iniciantes, existiram algumas estratégias a este respeito, buscando escapar de jogadores com bloqueios muito eficientes.

Importante destacar que a partir deste sistema estimula-se a escolha dos jogadores para determinadas funções, no caso desta, os levantadores. Tal escolha deve ser realizada por meio da reflexão sobre as vantagens e desvantagens dos jogadores e suas posições. ${ }^{11}$

\section{SISTEMA 6XO COM ESCOLHA DO LEVANTADOR E DO LOCAL DE LEVANTAMENTO}

Nesta situação, se escolhia, entre os 3 jogadores da rede, aquele que seria o levantador e ainda, de qual posição este iria atuar. Os problemas que surgiram foram:

- Qual a melhor opção de levantador? O processo de escolha de um levantador específico para a equipe vai avançando.

- De qual posição ele levantará? Surge a dinâmica das trocas de posição.

- Quando a melhor opção de levantador sair da rede, qual o novo escolhido? A escolha de pelo menos outro levantador também vai sendo concretizada, caminhando para o próximo sistema de jogo.

Conexões: revista da Faculdade de Educação Física da UNICAMP, Campinas, v. 13, n. 4, p. 165-177, out./dez. 2015. ISSN: 1983-9030. 


\section{SISTEMA 4X2}

O sistema 4X2 representa uma forma mais avançada do que a descrita anteriormente (6X0), exigindo a especialização de 4 jogadores atacantes e 2 jogadores levantadores. Estes últimos se dispõem na quadra de forma que sempre haja um deles atuando na zona de ataque e outro na zona de defesa.

Ao assumir este sistema o grupo já vivenciou individualmente todas as posições e funções. Permitiu-se que avaliassem seus colegas e a si mesmo, considerando desejos e habilidades e as possíveis combinações na equipe. Sendo assim, partir para um sistema onde se especifique 4 jogadores especializados em atacar e outros 2 para serem os levantadores representou um processo de construção consciente e coletivo.

Os grupos poderiam realizar algumas possibilidades que, em geral, se diferencia de outros formados sem este processo criativo:

- Na necessidade de trocar qualquer um dos levantadores, todos os demais jogadores são capacitados para assumir, visto que tiveram boa vivência nesta função;

- Seria possível jogar com o levantamento partindo de qualquer local da rede, visto terem vivenciado todas as situações;

- As discussões táticas eram realizadas com maior profundidade diante da compreensão do processo construído;

- Em situações pontuais adversas, a exemplo de uma recepção direcionada para o local errado, o atacante assumia a função do levantador sem maiores prejuízos no desempenho do jogo;

- Quais as características de cada levantador? Os atacantes iniciaram a identificação e adequação de seus posicionamentos e deslocamentos conforme as características de cada levantador. Como exemplo, quando uma recepção exigia do levantador executar o levantamento de uma distância muito grande que

Conexões: revista da Faculdade de Educação Física da UNICAMP, Campinas, v. 13, n. 4, p. 165-177, out./dez. 2015. ISSN: 1983-9030. 
normalmente não seria possível, o atacante se deslocava de forma a diminuir este espaço para conseguir atacar.

\section{SISTEMA 4X2 COM INFILTRAÇÃO}

Nesta situação iniciou-se o estímulo por buscar o maior número de atacantes na rede, com a inclusão da infiltração, isto é, o levantador que estava no fundo infiltrava para levantar e o levantador que estava na rede passa a ser atacante.

Inicialmente, as infiltrações ocorreram somente no momento da recepção do saque para que houvesse melhor compreensão da estratégia, visto que neste momento o jogo está interrompido, reiniciando-o apenas após o saque, o que proporciona maior tempo para verificação dos posicionamentos e combinações de jogadas. Posteriormente, à medida que os levantadores se sentiam mais apropriados desta dinâmica, informavam para o próprio grupo que iriam infiltrar em outras situações como em contra ataques.

Alguns problemas que os grupos precisaram resolver:

- Qual o posicionamento que devemos assumir no momento do saque adversário para realizar a infiltração? Diante da estratégia de colocar o levantador do fundo mais próximo da rede para levantar, mas preservar as relações de posicionamento entre todos os jogadores conforme dita a regra, algumas opções foram apresentadas pelo professor, vivenciadas e discutidas para se determinar a formação de recepção de saque adotada;

- Como aproveitar os 3 atacantes da rede? Pela primeira vez foi possível ter 3 opções de ataque na mesma rede. Investigando o que outras equipes, incluindo as de alto rendimento executavam, criaram-se estratégias de ataque combinando os atacantes da rede;

- Quais as características de cada atacante? Cada levantador passou a dedicar maior atenção às individualidades de cada atacante, iniciando a elaboração de tipos de levantamento para cada jogador;

Conexões: revista da Faculdade de Educação Física da UNICAMP, Campinas, v. 13, n. 4, p. 165-177, out./dez. 2015. ISSN: 1983-9030. 


\section{SISTEMA 5X1}

Este sistema foi assumido pelas 2 equipes após larga vivência no sistema anterior culminando com a diferença acentuada no desempenho entre os levantadores. É o mais avançado e dinâmico, envolvendo a situação de infiltração do levantador quando este está na zona de defesa e avança para a zona de ataque para realizar o levantamento, retornando à posição anterior após sua atuação. Trata-se de uma estratégia que exige muito entendimento de seus processos, envolvendo trocas, especialização de funções e posicionamentos diferenciados na defesa, ataque e recepção de saque.

Na equipe masculina a escolha do levantador titular exigiu muita reflexão e entendimento das possibilidades de atuação, visto que o melhor levantador era também, um bom atacante. No entanto, em decisão coletiva, resolveu-se que o único levantador a ser titular neste sistema $5 \mathrm{X} 1$ seria o melhor, mesmo que a equipe perdesse um bom atacante. Por outro lado, como levantador mais habilidoso e inteligente ele poderia colaborar com a qualidade do ataque dos demais, apostando ser mais adequado à equipe.

Esta situação demonstrou maturidade do grupo e mais especificamente do próprio levantador que preferia atuar como atacante, mas que se submeteu ao combinado coletivo em favor da equipe.

Na equipe feminina este processo não foi semelhante, pois as levantadoras não apresentavam destaque no desempenho como atacantes, portanto, a melhor passou a ser titular e a quinta atacante passou a integrar o grupo titular.

\section{CONCLUSÃO}

Nas duas oportunidades de implantação desta proposta, cada etapa descrita durou pelo menos 4 meses, o que proporcionou explorar todas as possibilidades sem pressa ou atropelos. Em ambas percebeu-se no grupo um bom nível de compreensão da dinâmica do jogo, suas possibilidades e necessidades técnicas, táticas e relações interpessoais, sendo

Conexões: revista da Faculdade de Educação Física da UNICAMP, Campinas, v. 13, n. 4, p. 165-177, out./dez. 2015. ISSN: 1983-9030. 
expressas na forma como atuavam em quadra como também nas discussões sobre seus desempenhos.

Outro fator importante na defesa desta proposta é a oferta de vivência ampla nas diversas situações da modalidade, afastando-se da especialização precoce e suas possíveis consequências em uma oportunidade esportiva mais pobre, limitando-se às funções de uma posição específica, o que infelizmente é comum no ensino do voleibol, a exemplo do jogador que tem maior estatura e desde muito cedo atua sempre como jogador de meio de rede, por ter maiores condições de bloquear.

Diante das experiências verificadas nestes 2 processos de construção tática conclui-se que oferecer a oportunidade dos alunos/atletas refletirem e compreenderem a dinâmica do voleibol de forma planejada e em longo prazo, sendo cuidadoso para explorar as diferentes fases, pode oferecer uma trajetória de aprendizado profundo tanto nas questões técnicas e táticas da modalidade quanto nas relações de respeito às individualidades, de ofertar oportunidades a todos, de cooperação e trabalho em equipe.

\section{REFERÊNCIAS}

${ }^{1}$ LAMARTINE, C. (Org.). Atlas do esporte no Brasil. Rio de Janeiro: Shape, 2005.

2MARCHI JUNIOR, W. “Sacando” o voleibol. São Paulo: Hucitec: Ed. da Unijuí, 2004.

${ }^{3}$ BIZZOCCHI, C. O voleibol de alto rendimento: da iniciação à competição. Barueri: Manole, 2008.

${ }^{4}$ REVERDITO, R. S.; SCAGLIA, A. J. Pedagogia do esporte: jogos coletivos de invasão. São Paulo: Phorte, 2009.

${ }^{5}$ GRECO, P. J. Iniciação esportiva universal. Belo Horizonte: Ed. da UFMG, 1998.

Conexões: revista da Faculdade de Educação Física da UNICAMP, Campinas, v. 13, n. 4, p. 165-177, out./dez. 2015. ISSN: 1983-9030. 
${ }^{6}$ KROGER, C.; ROTH, K. Escola da bola: um abc para iniciantes nos jogos esportivos. São Paulo: Phorte, 2002.

${ }^{7}$ OSLIN, J. L. Tactical approaches to teaching games: "are. Journal of Physical Education, Recreation \& Dance, Reston, v. 67, n. 1, p. 27, jan. 1996.

${ }^{8}$ SOUZA, A. J. É jogando que se aprende: o caso do voleibol. In: NISTA-PICOLLO, V. L. (Org.). Pedagogia dos esportes. Campinas: Papirus, 1999.

${ }^{9}$ GRIFFIN, L. L.; MITCHELL, S. A.; OSLIN, J. L. Teaching sports concepts and skills: a tactical games approach. Champaign: Human Kinects, 1997.

${ }^{10}$ GRAÇA, A.; OLIVEIRA, J. (Org.). O ensino dos jogos desportivos. 2. ed. Porto: Faculdade de ciências do desporte e de educação física. Centro de estudos dos jogos desportivos, 1995.

${ }^{11}$ HIRAMA, L. K. et al. Propostas interacionistas em pedagogia do esporte: aproximações e características. Conexões, Campinas, v. 12, n. 4, p. 51-68, out./dez. 2014.

Recebido em: 10 ago. 2015

Aceito em:21 out. 2015 Contato: leopoldohirama@yahoo.com.br

Conexões: revista da Faculdade de Educação Física da UNICAMP, Campinas, v. 13, n. 4, p. 165-177, out./dez. 2015. ISSN: 1983-9030. 